\title{
$\mathrm{DME}$ 생산공정에서 메탄올을 이용한 이산화탄소 제거 공정 연구
}

\author{
조두희 ${ }^{1}$, 노재현 ${ }^{1}$, 김동선 ${ }^{1}$, 조정호 ${ }^{*}$ \\ ${ }^{1}$ 공주대학교 화학공학부
}

\section{A Study for Carbon dioxide Removal Process Using Methanol Solvent in DME Manufacture Process}

\author{
Duhee Cho ${ }^{1}$, Jaehyun Rho $^{1}$, Dong Sun Kim ${ }^{1}$ and Jungho Cho ${ }^{1^{*}}$ \\ ${ }^{1}$ Department of Chemical Engineering, Kong Ju National University
}

\begin{abstract}
요 약 본 연구에서는 Dimethyl ether (DME) 생산 공정 중에 포함되어 있는 이산화탄소 제거를 위한 용매로써 메탄 올 수용액을 사용하는 공정에 대한 전산모사를 수행하였다. 공정모사를 위하여 Aspen tech 사의 Aspen Plus release 7.3을 사용하였으며, 열역학 모델식으로는 PC-SAFT 모델식을 사용하였다. PC-SAFT 모델식에서 필요한 이성분계 상 호작용 매개변수를 결정하기 위하여 실험 데이터를 수집하고 회귀분석을 통해 새롭게 결정하였으며, 결정한 매개변수 의 정확성은 실험 데이타와의 비교를 통해 검증하였다. 한편, 이러한 모델식과 검증한 매개변수를 사용하여 공정을 모델링 하였으며 최적 순환유량과 운전압력 그리고 원료 주입단 등을 결정하여 공정 최적화를 수행하였다.
\end{abstract}

\begin{abstract}
In this study, simulation works have been performed for the modeling of $\mathrm{CO}_{2}$ removal process contained in the DME production process through an absorber-stripper system using methanol aqueous solution. Aspen Plus release 7.3 in AspenTech company was utilized as a simulation tool and PC-SAFT modeling equation of state was used as a thermodynamic model. Fitting parameters built-in PC-SAFT model was determined by regressing experimental data, predicted results using PC-SAFT model were compared with experimental data in order to verify the exactness of the thermodynamic model. Optimization works have been performed to reduce the utility consumptions using solvent circulation rate, column operating pressure and feed stage location as manipulated variables.
\end{abstract}

Key Words : Dimethyl ether, PC-SAFT, Methanol solvent, Carbon dioxide, Simulation, Optimization

\section{1. 서론}

디메틸에테르(di-methyl ether, DME)는 천연가스뿐만 아니라 석탄과 바이오매스에서 생산되는 합성가스로부터 직접합성 또는 메탄올을 탈수해서 제조하는 간접합성 방 법으로 생산이 가능하다[1-2]. 그리고 DME는 물성이 액 화석유가스(liquified petroleum gas, LPG)와 유사하여 기 존의 LPG 유통 인프라구조를 이용하여 저렴한 비용으로 수송용, 가정용 및 상업용으로 보급이 가능한 연료이다.
Fig. 1에는 천연가스로부터 합성가스를 생산해내고 합성 가스로 부터 DME를 생산하는 공정의 개략도를 나타내 었다. 이러한 DME 생산 기술의 가장 중요한 측면의 하 나로 공정 중에 이산화탄소의 농도를 조절하는 것이다. 특히 DME 합성 반응기로 유입되는 원료 중에 이산화탄 소가 $3 \mathrm{~mol} \%$ 이상이 포함될 경우 $\mathrm{DME}$ 생산성이 급격히 떨어지는 문제가 발생될 수 있으며 $8 \mathrm{~mol} \%$ 이상의 이산 화탄소가 DME 합성반응기로 유입되면 DME 생산성 저 하뿐만 아니라 미 반응된 합성가스의 유량이 증가되면서

본 연구는 국토해양부 $\mathrm{LNG}$ 플랜트사업단의 연구비지원에 의해 수행되었습니다.

"Corresponding Author : Jungho Cho(Kong Ju National Univ.)

Tel: +82-10-9918-9366 email: jhcho@kongju.ac.kr

Received January 23, 2013 Revised February 21, 2013 Accepted March 7, 2013 
$\mathrm{DME}$ 합성반응기 후단공정인 $\mathrm{DME}$ 분리정제 영역에서 정상상태를 벗어난 운전이 전개됨으로 이산화탄소는 반 드시 제거되어야 한다[3-4]. 이로 인해 삼중개질반응 (tri-reformer)에서 생성된 혼합물이 DME 합성반응기로 유입되기 전 이산화탄소는 이산화탄소 제거 공정 $\left(\mathrm{CO}_{2}\right.$ removal section)에서 $99 \%$ 정도 제거되어야 한다. 그리고 제거된 이산화탄소는 개질기로 재순환시켜 원료로 재사 용되어진다. Table 1에는 한국가스공사의 일일 10ton DME 생산기준의 데모플랜트(demo plant)에서 이산화탄 소 제거 공정으로 유입되는 원료 조성 및 유량을 나타내 었다. 유입되는 기체의 총 유량은 $79.78 \mathrm{kmol} / \mathrm{hr}$ 가 되며 이중에서 일산화탄소와 수소의 유량은 거의 1:1 비율로 각각 $32.31 \mathrm{kmol} / \mathrm{hr}$ 와 $35.26 \mathrm{kmol} / \mathrm{hr}$ 가 된다. 그리고 이산 화탄소의 유량은 $11.14 \mathrm{kmol} / \mathrm{hr}$ 으로 함량은 약 13.96 $\mathrm{mol} \%$ 정도가 된다.

한편, 이산화탄소 제거 공정에서 흡수제의 선정은 $\mathrm{DME}$ 생산 플랜트 건설비용 및 운전비용 면에서 매우 큰 영향을 차지하며 공정의 효율성면에서도 반드시 고려해 보아야 할 문제인데 본 연구에서는 이산화탄소 흡수제 로써 메탄올(methanol; $\left.\mathrm{CH}_{3} \mathrm{OH}\right)$ 을 사용하는 공정을 모델 링하고 장치 사이징과 유틸리티 비용을 도출하였다.

메탄올을 이용한 이산화탄소 제거공정은 메탄올에 대 한 $\mathrm{CO}_{2}$ 의 높은 용해도를 이용하여 원료 중에 포함되어 있는 $\mathrm{CO}_{2}$ 를 용해시켜 제거하게 된다. 메탄올의 경우 $\mathrm{DME}$ 합성 반응시 생성되는 물질로써 공정상에 순환되 는 물질이므로 DME 생산 공정 중에 생성되는 메탄올을 정제하여 사용할 수 있다는 큰 이점이 있지만 원료 중에 물이 포함되어 있는 경우 순환되는 용매 중에 물의 함량 이 점점 증가하여 메탄올의 순도가 낮아지게 되므로 기 본적인 흡수탑과 탈거탑 뿐만 아니라 메탄올 정제 컬럼 이 추가적으로 필요하다. Fig. 2에는 이러한 공정도를 나 타내었다. 하지만 본 공정과 같이 메탄올 용매 재생탑 (T03)으로 유입되는 원료(No. 8) 중에 메탄올의 함량이 높은 경우에는 증류탑 하부로 내려가는 대부분의 메탄올 을 다시 탑상부로 끓여 올려야 하기 때문에 재비기에서 나가는 액상보다 증류탑으로 재순환시키는 증기의 양이 (boil-up ratio) 크고 재비기의 에너지 소모량(heat duty)도 크게 소요되게 된다. 그로인해 흡수탑(T01)과 탈거탑 (T02)에 비해 장치 사이징이 크고 재비기의 스팀(steam) 소모량도 많게 된다. 따라서 본 연구에서는 메탄올 용매 재생탑(T03)의 에너지 소모량과 장치 사이징을 최대한으 로 줄이기 위하여 Fig. 3 과 같이 이산화탄소 탈거탑(T02) 하부에서 나오는 스트림(No. 8) 중 일부만을 메탄올 용매 재생탑(T03)으로 주입시키는 방식으로 택하였다.
[Table 1] feed stream information

\begin{tabular}{ccc}
\hline Component & $\mathrm{kmol} / \mathrm{hr}$ & Mole\% \\
\hline $\mathrm{CH}_{4}$ & 0.92 & 1.15 \\
$\mathrm{CO}_{2}$ & 11.14 & 13.96 \\
$\mathrm{H}_{2}$ & 35.26 & 44.2 \\
$\mathrm{CO}$ & 32.31 & 40.5 \\
$\mathrm{H}_{2} \mathrm{O}$ & 0.15 & 0.19 \\
Total flow $(\mathrm{kmol} / \mathrm{hr})$ & 79.78 & 100.00 \\
Temperature $(\mathrm{K})$ & $303.15\left(30^{\circ} \mathrm{C}\right)$ \\
Pressure $(\mathrm{kPa})$ & \multicolumn{2}{c}{$6,000.00$} \\
\hline
\end{tabular}

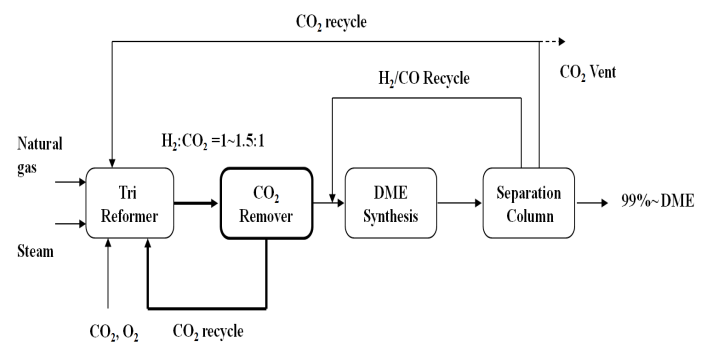

[Fig. 1] DME manufacture process.

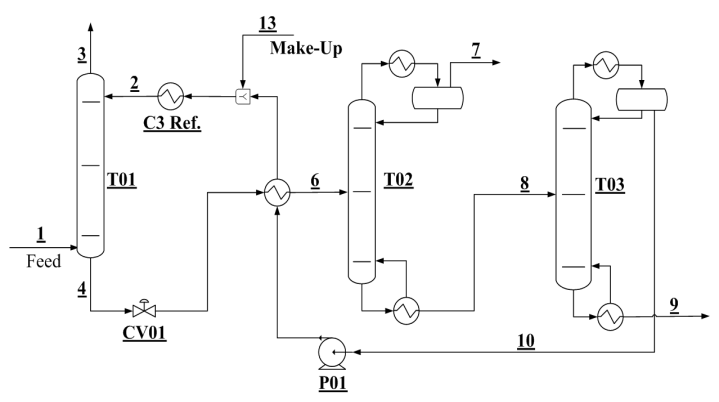

[Fig. 2] A schematic diagram for the $\mathrm{CO}_{2}$ capture process using aqueous methanol solution (Type 1).

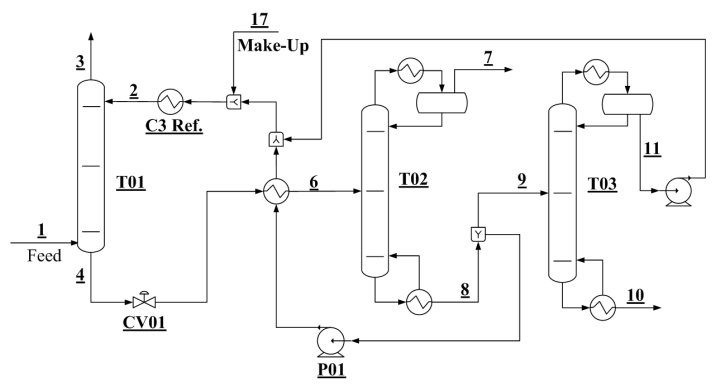

[Fig. 3] A schematic diagram for the $\mathrm{CO}_{2}$ capture process using aqueous methanol solution (Type 2). 


\section{2. 이론}

\section{1 열역학의 모델식 선정}

본 연구에서는 이산화탄소 제거 공정을 모사하기 위하 여 PC-SAFT(perturebed-chain statistical associating fluid theory) 상태 방정식[5-6]을 사용하였다. PC-SAFT 상태방 정식은 열역학적 섭동이론(theory of perturbation)을 기초 로하여 Huang와 Radosz[7-8]가 개발한 SAFT 모델식에서 분산(dispersion)항을 수정한 모델식으로써 계의 residual helmholtz 자유에너지가 주어지고, 이것을 바탕으로 각상 의 퓨개시티 계수와 계의 압축인자와 같은 필요한 열역 학적 특성을 계산하게 된다. PC-SAFT 모델식에서 residual helmholtz 자유에너지에 기여하는 항으로는 강체 구(hard sphere)항, 사슬(chain)항, 분산(dispersion)항, 회 합(association)항이 고려되며 식 (1)과 같이 표현된다.

$$
\tilde{A}^{r e s}=\widetilde{A}^{h s}+\widetilde{A}^{d i s p}+\widetilde{A}^{c h a i n}+\widetilde{A}^{a s s o c}
$$

위 식(1)에서 는 세그먼트-세그먼트 간의 반발력으로 인 해 발생되는 residual helmholtz 자유에너지에 기여하는 강 구체(hard sphare)항으로 Charnahan과 Starling[9]에 의해 발 표된 것이며 식(2)과 같이 표현된다.

$$
\frac{\tilde{A}^{h s}}{N k T}=\frac{6}{\pi \rho}\left[\frac{\left(\zeta_{2}\right)^{3}+3 \zeta_{1} \zeta_{2} \zeta_{3}-3 \zeta_{1} \zeta_{2}\left(\zeta_{3}\right)^{2}}{\zeta_{3}\left(1-\zeta_{3}\right)^{2}}-\left[\zeta_{3}-\frac{\left(\zeta_{2}\right)^{3}}{\left(\zeta_{3}\right)^{2}}\right] \ln \left(1-\zeta_{3}\right)\right]
$$

여기서 $\mathrm{N}, \mathrm{k}$, 그리고 $\mathrm{T}$ 는 각각 분자의 수, boltzmann 상수, 그리고 계의 온도를 나타내며 $\zeta_{n}$ 는 $\rho$ (molar density)의 함수로서 강체구들이 사슬을 형성할 때 Chapman에 의해 제안된 것으로 식(3)과 같다.

$$
\zeta_{n}=\frac{\pi}{6} \rho \sum_{i} x_{i} m_{i}\left(d_{i i}\right)^{n} \quad n \in 0,1,2,3
$$

위의 식에서 $x$ 는 몰분율이고 $m$ 은 몰당 세그먼트의 수를 의미한다. 또한 $d$ 는 온도의존성 세그먼트 지름으로 식(4)와 같이 표현된다.

$$
d_{i i}(T)=\sigma_{i i}\left[1-0.12 \exp \left(-3 \frac{\epsilon_{i i}}{k T}\right)\right]
$$

여기서 $\sigma_{i i}$ 는 온도에 무관한 세그먼트의 지름으로 순 수성분 매개변수이며, $\epsilon_{i i}$ 는 세그먼트-세그먼트간의 상호 작용 에너지로서 분산에너지(dispersion energy parameter)를
의미하는 순수성분 매개변수이다. 식(1)에서 $\widetilde{A}^{\text {chain }}$ 는 세그먼트들의 사슬을 형성함으로써 residual helmholtz 자 유에너지에 기여하는 항으로 다음과 같은 식(5)와 같이 표현된다.

$$
\frac{\widetilde{A}^{\text {chain }}}{N k T}=\sum_{i} x_{i}\left(1-m_{i}\right) \ln g_{i i}^{h s}\left(d_{i i}\right)
$$

식(1)에서 $\widetilde{A}^{a s s o c}$ 항은 Wertheim[10-11]의 열역학적 섭동이론에 기초하고 있으며 Chapman[12]에 의하여 유 도된 항으로서 수소결합과 같은 분자들간에 서로 회합으 로 인해 residual helmholtz 자유에너지에 기여하는 항이 다. 이 항은 식(6)에서 (8)과 같이 표현된다.

$$
\begin{aligned}
& \frac{\widetilde{A}^{\text {assoc }}}{N k T}=\sum_{i} x_{i}\left[\sum_{A_{i}}\left(\ln X^{A_{i}}-\frac{X^{A_{i}}}{2}\right)+\frac{M_{i}}{2}\right] \\
& X^{A_{i}}=\left[1+\rho \sum_{i} x_{i} \sum_{B_{j}} \rho_{j} X^{B_{j}} \Delta^{A_{i} B_{j}}\right]^{-1} \\
& \triangle^{A_{i} B_{j}}=d_{i j}^{3} g_{i j}\left(d_{i j}\right)^{\operatorname{seg}} k^{A_{i} B_{j}}\left[e^{\frac{\epsilon^{A}, B_{j}}{k T}}-1\right]
\end{aligned}
$$

여기서 $\epsilon^{A_{i} B_{j}} / k$ 는 $\mathrm{i}$ 성분의 회합자리 $\mathrm{A}$ 와 $\mathrm{j}$ 성분의 회합 자리 $\mathrm{B}$ 가 회합하기위해서 필요한 회합에너지(association energy)로서 순수성분의 매개변수이며, 또한 $k^{A_{i} B_{j}}$ 는 회 합부피(association volume)를 의미하며 순수성분 매개변 수이다.

마지막으로 식(1)에서 $\widetilde{A}^{d i s p}$ 항은 Gross와 Sadowski[5] 에 의해 제안되어 식(9)에서 식(12)와 같이 표현되어진다.

$$
\begin{aligned}
\frac{\tilde{A}^{\text {disp }}}{N k T}= & -2 \pi \rho I_{1}(\eta, \bar{m}) \sum_{i} \sum_{j} x_{i} x_{j} m_{i} m_{j}\left(\frac{\epsilon_{i j}}{k T}\right) \sigma_{i j}^{3} \\
& -\pi \rho \bar{m} C_{1} I_{2}(\eta, \bar{m}) \sum_{i} \sum_{j} x_{i} x_{j} m_{i} m_{j}\left(\frac{\epsilon_{i j}}{k T}\right)^{2} \sigma_{i j}^{3}
\end{aligned}
$$

한편, 위 식에서 $\bar{m}$ 는 다음과 같이 나타낼 수 있다.

$$
\bar{m}=\sum_{i} x_{i} m_{i}
$$

그리고 혼합물에서 화학성분이 다른 세그먼트 간의 파 라미터 $\sigma_{i j}$ 및 $\epsilon_{i j}$ 는 다음과 같은 혼합법칙(mixing rule)이 적용된다. 


$$
\begin{aligned}
& \sigma_{i j}=\frac{1}{2}\left(\sigma_{i i}+\sigma_{j j}\right) \\
& \epsilon_{i j}=\sqrt{\epsilon_{i i} \epsilon_{j j}}\left(1-k_{i j}\right)
\end{aligned}
$$

식(12)에서 나타낸 $k_{i j}$ 는 이성분계 상호작용 매개변수 로써 온도에 따른 이성분계의 기-액 상평형 실험 데이터 를 잘 추한하도록 회귀분석을 통해서 결정되어 진다. 식 (13)에는 온도에 따른 이성분계 쌍에 대한 $k_{i j}$ 의 관계식 을 표현하였다.

$$
k_{i j}=a_{i j}+b_{i j} / T_{r}+c_{i j} \ln T+d_{i j} T_{r}+e_{i j} T_{r}^{2}
$$

결국, PC-SAFT 상태방정식에서 각 순수성분에 대해 기본적으로 필요한 매개변수로는 segment의 크기에 해당 하는 $\sigma$, 각 분자에 포함되는 segment의 개수에 해당하는 $m$, 그리고 dispersion 상호작용 에너지를 의미하는 $\epsilon$ 이 며 추가적으로는 association 항에 대해서 association 에 너지를 의미하는 $\epsilon^{A_{i} B_{j}}$ 과 association 부피를 의미하는 $k^{A_{i} B_{j}}$ 가 필요하다. 그리고 화학종이 다른 두 성분들 간에 상호작용 매개변수(binary interaction parameters)로 $k_{i j}$ 이 필요하다.

\section{2 모델식의 매개변수 선정}

공정 모델링 및 공정설계에 있어 적절한 열역학 모델 식의 선정과 정확한 매개변수 선정은 매우 중요하다. Table 2에는 aspen plus version 7.3에 내장되어 있는 각 순수성분들에 대해 $\sigma, m, \epsilon$ 그리고 추가적으로 수분과 메탄올에 대해서는 $\epsilon^{A_{i} B_{j}}$ 와 $k^{A_{i} B_{j}}$ 값을 나타내었다.

[Table 2] PC-SAFT model pure parameters

\begin{tabular}{crrrrr}
\hline Comp. & $\epsilon$ & $\sigma$ & $m$ & $\epsilon^{A_{i} B_{j}}$ & $k^{A_{i} B_{j}}$ \\
\hline $\mathrm{CH}_{4}$ & 150.0300 & 3.7039 & 1.0000 & - & - \\
$\mathrm{CO}_{2}$ & 152.1010 & 2.5637 & 2.5692 & - & - \\
$\mathrm{H}_{2}$ & 12.5276 & 2.9729 & 0.8285 & - & - \\
$\mathrm{CO}$ & 93.0380 & 3.2829 & 1.2751 & - & - \\
$\mathrm{H}_{2} \mathrm{O}$ & 366.5100 & 3.0007 & 1.0656 & $1,525.6265$ & 0.0117 \\
$\mathrm{CH}_{3} \mathrm{OH}$ & 182.5608 & 2.8422 & 2.2436 & $2,580.0849$ & 0.0653 \\
\hline
\end{tabular}

한편, aspen plus version 7.3에 이성분계 상호작용 매 개변수가 내장되어 있지 않은 이성분계들에 대해서는 새 롭게 결정하기 위하여 관련 실험 데이터가 있는 문헌자
료들을 수집하고 Britt와 Luecke[13]가 제안한 알고리즘 과 목적함수로는 실험 데이터와 계산결과와의 온도, 압력 그리고 액상과 기상 각각의 몰 조성의 편차를 최소화하 는 Maximum-likelihood식을[14] 사용하여 회귀분석을 통 해 PC-SAFT 상태방정식의 이성분계 상호작용 매개변수 를 결정하였다. 전산모사를 위해 결정된 이성분계 상호작 용 매개변수는 Table 3 에 나타내었다. 그리고 결정된 상 호작용 매개변수에 대한 정확성을 검증하기 위하여 문헌 자료를 통해 수집한 실험 데이터 값과 Table 3 의 이성분 계 상호작용 매개변수를 적용한 PC-SAFT 상태방정식의 계산 값 간에 비교를 수행하였다. 대표적으로 이산화탄소 와 메탄올, 메탄올과 수분의 이성분계에 대한 추산결과를 Fig. 4와 Fig. 5에 나타내었다. 그 결과 실험 값을 비교적 근사한 차이로 추산해내는 것을 볼 수 있다.

[Table 3] Binary interaction parameter $k_{i j}$ for PC-SAFT equation of state model

\begin{tabular}{cccccc}
\hline Component i Component $\mathrm{j}$ & $A_{i j}$ & $B_{i j}$ & $C_{i j}$ & $\mathrm{~T}$ \\
\hline $\mathrm{CH}_{4}$ & $\mathrm{MEOH}$ & 0.04094 & -0.03682 & 0.00000 & $\mathrm{~K}$ \\
$\mathrm{H}_{2}$ & $\mathrm{MEOH}$ & -0.86047 & 0.37000 & 0.00000 & $\mathrm{~K}$ \\
$\mathrm{CO}$ & $\mathrm{MEOH}$ & 0.00000 & -0.02655 & -0.02142 & $\mathrm{~K}$ \\
$\mathrm{CO}_{2}$ & $\mathrm{MEOH}$ & 0.00000 & 0.00991 & 0.00443 & $\mathrm{~K}$ \\
$\mathrm{H}_{2} \mathrm{O}$ & $\mathrm{MEOH}$ & 0.00513 & -0.15198 & 0.00000 & $\mathrm{~K}$ \\
$\mathrm{CH}_{4}$ & $\mathrm{H}_{2} \mathrm{O}$ & 0.30366 & -0.49743 & 0.00000 & $\mathrm{~K}$ \\
$\mathrm{H}_{2}$ & $\mathrm{H}_{2} \mathrm{O}$ & -0.02327 & -1.05169 & 0.00000 & $\mathrm{~K}$ \\
$\mathrm{CO}$ & $\mathrm{H}_{2} \mathrm{O}$ & 0.17356 & -0.47734 & 0.00000 & $\mathrm{~K}$ \\
$\mathrm{CO}_{2}$ & $\mathrm{H}_{2} \mathrm{O}$ & 0.09364 & -0.18361 & 0.00000 & $\mathrm{~K}$ \\
\hline
\end{tabular}

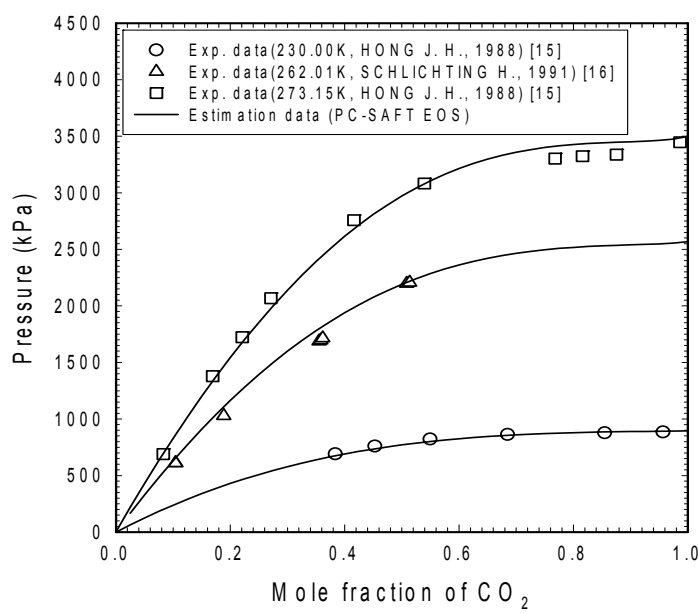

[Fig. 4] binary isothermal $\mathrm{P}-\mathrm{x}$ experimental data for carbon dioxide-methanol and its prediction with PC-SAFT equation of state. 


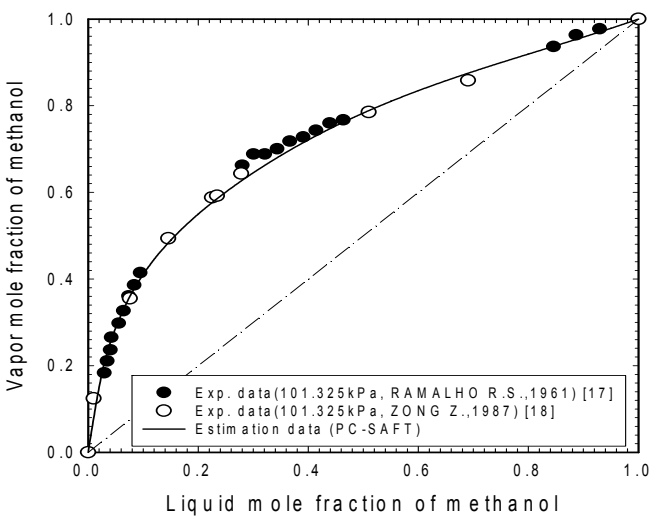

[Fig. 5] Experimental vs calculated equilibrium curves of methanol-water at $101.325 \mathrm{kPa}$.

\section{3. 메탄올을 이용한 이산화탄소 제거 공정 모사}

\section{1 흡수탑의 모델링}

Fig. 2의 공정도에 의하면 이산화탄소를 포함한 Table 1 의 원료가스는 흡수탑(absorber, T01) 하부로 주입되고 메탄올 용매는 프로판 냉동사이클(C3 Ref.)에 의해서 냉 각된 후 흡수탑 상부(No. 2)로 주입된다. 흡수탑에서는 메탄올 용매와 원료가스가 서로 향류로 접촉하면서 합성 가스 중에 함유되어 있는 이산화탄소를 메탄올 용매가 선택적으로 흡수하여 탑하부로(No. 4) 유출되게 된다. 본 연구에서는 메탄올 수용액의 농도는 상업용 농도에 해당 하는 $99.0 \mathrm{wt} \%$ 으로 결정하였으며, 용매의 공급온도는 프 로판 냉동 사이클을 이용하는 것으로 가정하여 253.15 $\mathrm{K}\left(-20^{\circ} \mathrm{C}\right)$ 으로 정하였다. 그리고 흡수탑 상부의 운전 압력 은 원료 압력보다 $200 \mathrm{kPa}$ 이 낮은 $5,800 \mathrm{kPa}$ 로 고정하였 으며, 흡수탑의 이론단수는 일반적인 흡수탑 단수로써 적 절한 6단으로 고정시켰다. 또한 흡수탑의 단 효율은 설계 회사에 따라 적용 기준치가 달라지나 대부분 $25.0 \%$ $33.0 \%$ 범위에서 선정된다. 따라서 본 연구에서는 $30 \%$ 기 준으로 설계하였다. 그 밖에 흡수탑 설계 조건에 대해서 는 Table 4에 나타내었다. 한편 흡수탑에서 변화시킬 수 있는 조절변수는 메탄올 용매의 순환유량인데 이는 이산 화탄소를 흡수탑하부(No. 4)로 원료대비 $99.0 \%$ 제거 하 는 유량으로 결정하였다. Fig. 6에는 용매의 순환유량에 따른 이산화탄소의 원료대비 탑하부로의 제거율을 나타 내었다. Fig. 6의 결과를 보면 $253.15 \mathrm{~K}$ 의 $99.0 \mathrm{wt} \%$ 메탄 올 용매를 사용하여 이산화탄소를 원료대비 $99.0 \%$ 제거 하기 위해 필요한 유량은 $188.23 \mathrm{kmol} / \mathrm{hr}$ 로 계산되었다.
[Table 4] design conditions for $\mathrm{CO}_{2}$ absorber

\begin{tabular}{|c|c|}
\hline Column & $\mathrm{CO}_{2}$ absorber \\
\hline Theoretical stage number & 6 \\
\hline $\begin{array}{l}\text { solvent feeding temperature to } \\
\text { absorber }(\mathrm{K})\end{array}$ & 253.15 \\
\hline column top pressure $(\mathrm{kPa})$ & $5,800.00$ \\
\hline column bottom pressure $(\mathrm{kPa})$ & $5,900.00$ \\
\hline $\mathrm{CO}_{2}$ removal ratio ${ }^{\mathrm{a}}(\%)$ & 99.00 \\
\hline stage efficiency (\%) & 30.00 \\
\hline Internal type & $\begin{array}{r}\text { Structured packing } \\
\text { (sulzer, 500Y) }\end{array}$ \\
\hline $\operatorname{HETP}^{\mathrm{b}}(\mathrm{mm})$ & 350.00 \\
\hline
\end{tabular}

a: [1-(amounts of $\mathrm{CO}_{2}$ in treat gas/amounts of $\mathrm{CO}_{2}$ in feed gas) $] \times 100 \%$

b: height equivalent to a theoretical plate

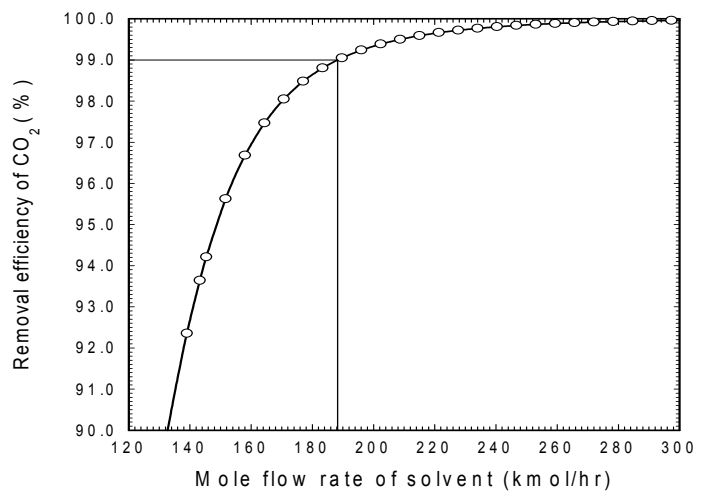

[Fig. 6] removal efficiency of carbon dioxide at absorber with various flow rate of solvent $(99.0 \mathrm{wt} \%$ methanol aq.).

\section{2 탈거탑의 모델링}

이산화탄소가 다량 함유되어 있는 흡수탑(T01) 하부 스트림(No. 4)은 열교환된 후 탈거탑(T02)의 중간으로 주 입된다. 탈거탑에서는 탈거탑의 운전압력과 원료 주입단 의 위치에 따라서 초기 장치 투자비용과 운전비용이 결 정될 수 있다. 우선 탈거탑의 운전압력에 대해서 압력을 높이면 증기상의 부피가 줄어들기 때문에 탈거탑의 직경 을 줄일 수 있지만 분리효율이 떨어지기 때문에 탑의 높 이가 늘어나게 된다. 또한 운전압력을 높이면 탑상부의 온도가 상승하기 때문에 냉각수와 대수평균 온도차가 커 지게 되어 응축기의 전열면적이 줄어들게 된다. 하지만 탈거탑 하부의 운전 온도도 높아지게 되어 고압의 스팀 을 사용해야 하는 단점이 발생한다. 이러한 조건을 고려 하여 탈거탑의 운전압력은 탑상부에서 냉각수(cooling water)를 사용할 수 있는 충분한 온도 $318.15 \mathrm{~K}\left(45^{\circ} \mathrm{C}\right)$ 가 
되는 $12.0 \mathrm{bar}$ 로 고정하였다. 그 밖에 탈거탑 설계 조건에 대해서는 Table 5에 나타내었다.

[Table 5] design conditions for $\mathrm{CO}_{2}$ stripper

\begin{tabular}{lr}
\hline \multicolumn{1}{c}{ column } & $\mathrm{CO}_{2}$ stripper \\
\hline Theoretical stage number & 12 \\
Reflux ratio & Manipulated \\
Target $\mathrm{CO}_{2}$ removal ratio ${ }^{\mathrm{a}}(\%)$ & 99.99 \\
Condenser type & Sub-cooled \\
Condenser pressure $(\mathrm{kPa})$ & 1200.00 \\
Reflux drum temperature $(\mathrm{K})$ & 318.15 \\
Cooling water supply $(\mathrm{K})$ & 303.15 \\
Cooling water return $(\mathrm{K})$ & 313.15 \\
Column top pressure $(\mathrm{kPa})$ & 1220.00 \\
Column Bottom pressure $(\mathrm{kPa})$ & 1250.00 \\
Steam condition $(\mathrm{K})$ & $473.15 \mathrm{~K}$ saturated \\
Internal type & Structured packing \\
HETP (mm) & (sulzer, 500Y) \\
& 300.00 \\
\hline
\end{tabular}

a: [1-(amounts of $\mathrm{CO}_{2}$ in treat gas/amounts of $\mathrm{CO}_{2}$ in feed gas) $] \times 100 \%$

한편 탈거탑의 총 이론단수는 응축기와 재비기를 포함 하여 12 단으로 고정하였으며 제 1단이 응축기에 해당하 고 제 12 단이 재비기에 해당한다. 그리고 Fig. 7에는 최적 의 원료 주입단을 선정하기 위하여 원료 주입단의 위치 변화에 따른 재비기의 에너지 소모량(heat duty)의 변화 를 나타내었다.

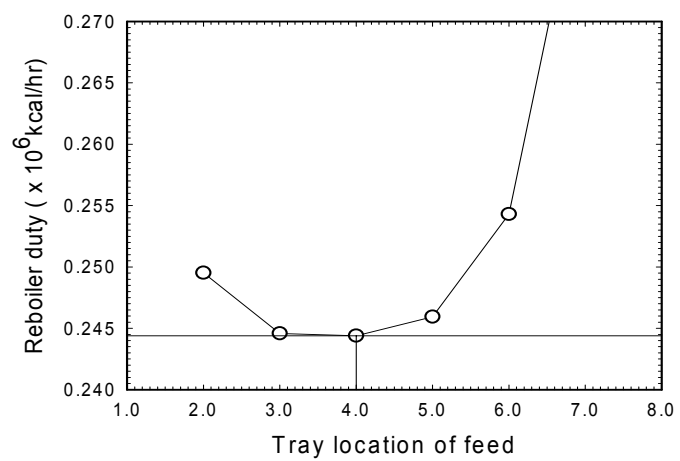

[Fig. 7] Optimization of feed stage location which minimizes the reboiler heat duty at $\mathrm{CO}_{2}$ stripper.

그 결과 재비기의 heat duty를 최소화시키는 원료 주입 단의 위치는 제 5 단이며 이때 재비기의 heat duty는 $0.2444 \times 10^{6} \mathrm{kcal} / \mathrm{hr}$ 로 계산되었다.

\section{3 메탄올 용매 재생탑의 모델링}

본 공정에서 흡수탑(T01)으로 주입되는 메탄올 용매
의 순도는 $99.00 \mathrm{wt} \%$ 이지만 원료(No. 1) 중에 포함되어 있는 소량의 수분으로 인해 이산화탄소 탈거탑 하부로 (No. 4) 나오는 메탄올 용매의 순도는 $98.95 \mathrm{wt} \%$ 가 된다. 이와 같이 용매가 순환됨에 따라 공정 내에 수분의 양이 점점 증가하기 때문에 안정적인 운전을 위해서는 메탄올 물 분리컬럼인 메탄올 용매 재생탑(T03)이 필요하게 된 다. 본 연구에서는 이산화탄소 탈거탑(T02) 하부에서 나 오는 스트림(No. 8) 중 일부만을 메탄올 재생탑으로 주입 시키는 방식Fig. 2으로 택하였다. 메탄올 용매 재생탑으 로 주입된 메탄올 수용액은 탑상부로(No. 11) $99.92 \mathrm{wt} \%$ 까지 정제되어지고 탑하부로는(No. 10) 원료 중에 포함 되어 있던 수분보다 약간 많은 양이 나가게 되는데 이 양 만큼은 공정 중 손실된 메탄올을 보충해 줄 때 함께 주입 되게 된다. 한편 메탄올 용매 재생탑으로 주입되지 않은 대부분의 메탄올 수용액은 메탄올 용매 재생탑에서 고순 도로 정제된 메탄올 수용액과 다시 혼합되어 흡수탑의 용매로 필요한 순도인 $99.00 \mathrm{wt} \%$ 로 맞추어진다. 그리고 공정 중에 손실된 양만큼 $99.00 \mathrm{wt} \%$ 메탄올 수용액을 보 충해 줌으로써 용매 순환 사이클이 완성되게 된다.

본 연구에서는 메탄올 용매 재생탑(T03)의 전산모사 를 수행하기 위해서 탑상에서 메탄올의 순도가 99.92 $\mathrm{wt} \%$ 가 되고 탑저에서 수분의 함량이 $99.90 \mathrm{wt} \%$ 가 되도 록 하는 증류탑의 최소이론단수와 최소 환류비를 결정한 다음에 이에 대한 케이스 조사(case study)를 수행하여 최 적의 이론단수를 결정하였다. Fig. 8에는 환류비와 이론 단수 사이의 관계를 그래프로 나타내었다.

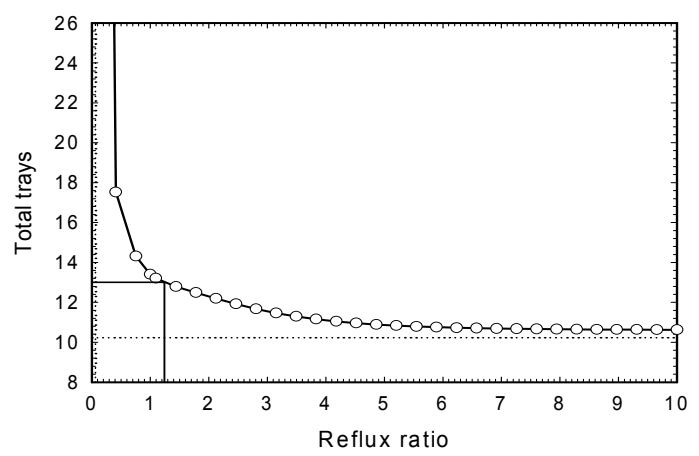

[Fig. 8] relation between reflux ratio and theoretical number of stage at T03 Column.

환류비가 많은 쪽에서 운전할 경우에는 이론단수는 줄어들게 되어 초기 장치 투자비용은 줄어들지만 운전비 용이 늘어나게 되고 반대로 환류비가 적은 쪽에서 운전 할 경우에는 운전비용은 줄일 수 있지만 이론단수가 증 가하게 되어 초기 장치투자비용이 늘어날 것이다. 따라서 
총 투자비용인 장치투자비용과 운전비용의 합을 최소화 시키기 위해서는 환류비와 이론단수 사이의 기울기가 가 장 급격하게 기울어지는 이론단수 13 단 부근에서 조업하 는 것이 최적의 설계 조건이 됨을 알 수 있다. 따라서 메 탄올 용매 재생탑의 이론단수는 재비기 에너지 소모량 (heat duty)을 줄일 수 있도록 환류비를 약간 줄이는 방향 으로 하여 13 단으로 결정하였다. 그리고 이산화탄소 탈 거탑과 동일한 방법으로 원료 주입단에 따른 재비기의 heat duty변화량을 통해 최적의 원료 주입단을 결정하였 으며 그 결과를 Fig. 9에 나타내었다. Fig. 9를 보면 최적 의 원료 주입단은 5 단이 되면 이 때 재비기 heat duty는 $0.1686 \times 10^{6} \mathrm{kcal} / \mathrm{hr}$ 가 된다. 그 밖에 메탄올 용매 재생탑 설계 조건에 대해서는 Table 6에 나타내었다.

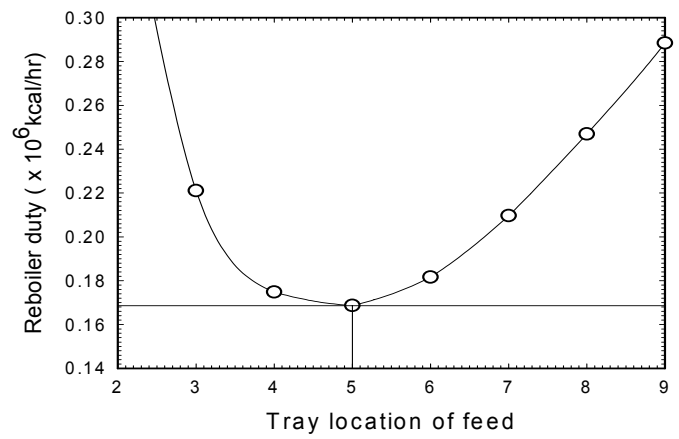

[Fig. 9] optimization of feed stage location which minimizes the reboiler heat duty at Methanol purification column.

[Table 6] design conditions for methanol solvent recovery column

\begin{tabular}{lr}
\hline \multicolumn{1}{c}{ Column } & \multicolumn{1}{c}{$\begin{array}{c}\text { Methanol } \\
\text { purification column }\end{array}$} \\
\hline Theoretical stage number & 13.00 \\
Feed stage location & 5.00 \\
Reflux ratio & Manipulated \\
Target methanol purity in top & $99.90 \%$ \\
product (\%) & Sub-cooled \\
Condenser type & $120.00 \mathrm{kPa}$ \\
Condenser pressure (kPa) & 318.15 \\
Reflux drum temperature (K) & 303.15 \\
Cooling water supply (K) & 313.15 \\
Cooling water return (K) & 140.00 \\
Column top pressure (kPa) & 140.76 \\
Column Bottom pressure (kPa) & 473.15K saturated \\
Steam condition (K) & Structured Packing \\
Internal type & (sulzer, 500Y) \\
HETP (mm) & 300.00 \\
\hline
\end{tabular}

\section{4 프로판 냉동 사이클의 모델링}

$99.0 \mathrm{wt} \%$ 의 메탄올 용매의 공급온도를 $312.15 \mathrm{~K}(3$ $\left.9^{\circ} \mathrm{C}\right)$ 에서 $253.15 \mathrm{~K}\left(-20^{\circ} \mathrm{C}\right)$ 로 낮추기 위해서는 냉동 사이 클의 가동이 필수적이다. 증기 재압축을 이용한 냉동 사 이클에 대한 개념도는 Fig. 10에 나타내었다. Fig. 10에 의하면 프로판 냉매는 압축기를 통해 저압 상태에서 고 압으로 압축되어진 후 응축기에 의해서 $318.15 \mathrm{~K}\left(45^{\circ} \mathrm{C}\right)$ 까지 냉각 및 응축되어진다. 이때 압축기 후단의 압력은 $318.15 \mathrm{~K}$ 에서 프로판의 기포점 압력과 같게 된다. 그리고 응축기 후단의 액화된 냉매는 줄-톰슨 팽창 밸브에 의해 서 충분히 낮은 온도까지 떨어지게 되는데 본 연구에서 는 팽창되는 압력을 외부 공기의 유입을 방지하기 위해 $130 \mathrm{kPa}$ 로 정하였다. 즉, 냉매의 온도를 줄-톰슨 팽창 밸 브에서 $130 \mathrm{kPa}$ 까지 팽창되었을 때의 떨어지는 온도가 된다. 한편, 냉매는 줄-톰슨 팽창 후에 기상과 액상이 동 시에 존재하게 되는데 기-액 분리기에 의해서 기상은 압 축기 전단으로 보내지고 액상류만을 증발기로 보내서 프 로판의 잠열을 통해 냉동 효과를 얻어내게 된다. Table 7 에는 본 공정에서 필요한 냉동 사이클의 조업조건과 조 업 결과에 대해서 요약해 놓았다.

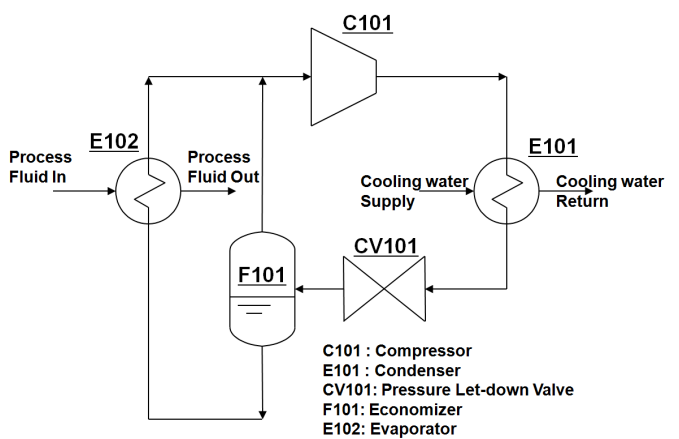

[Fig. 10] A schematic diagram for refrigeration cycle using propane as a refrigerant.

[Table 7] summary of computer simulation results for refrigeration cycle

\begin{tabular}{clr}
\hline Step & \multicolumn{1}{c}{ Item } & \multicolumn{1}{c}{ Result } \\
\hline 1 & Evaporator heat duty $\left(\times 10^{6} \mathrm{kcal} / \mathrm{hr}\right)$ & 0.1988 \\
2 & Comp. discharge pressure $(\mathrm{kPa})$ & $1,588.50$ \\
3 & Expansion valve outlet pressure $(\mathrm{kPa})$ & 130.00 \\
4 & Ref. temp. at expansion valve outlet $(\mathrm{K})$ & 236.80 \\
5 & Ref. feeding rate to evaporator $(\mathrm{kg} / \mathrm{hr})$ & $1,971.33$
\end{tabular}


6 Total ref. circulation rate $(\mathrm{kg} / \mathrm{hr})$

7 Comp. power consumption, $(\eta=0.7)(\mathrm{kW})$

8 Condenser heat duty $\left(\times 10^{6} \mathrm{kcal} / \mathrm{hr}\right)$

9 Cooling water supply (K)

10 Cooling water return $(\mathrm{K})$

11 Cooling water consumption $(\mathrm{kg} / \mathrm{hr})$
$3,970.30$

187.20

0.3598

303.15

313.15

$36,146.72$

\section{4. 결론}

본 연구에서는 현재 가스공사에서 운전되고 있는 일일 10 톤 DME 생산공정에서 이산화탄소 제거 공정으로 유 입되는 원료를 조성으로 하였고 메탄올 용매를 사용하여 $\mathrm{DME}$ 생산 공정 중에 합성가스 개질반응기 후단에서 나 오는 이산화탄소를 원료대비 $99.0 \%$ 제거하는 공정을 PC-SAFT 상태방정식을 사용하여 모델링하였다. 한편 정 확한 모델링을 위해 필요한 PC-SAFT 모델식의 이성분계 상호작용 매개변수는 회귀분석을 통해 새롭게 결정하였 으며 결정한 매개변수의 정확성은 실험 데이타와의 비교 를 통해 검증하였다. 또한 정제탑을 추가적으로 설치함으 로써 DME 합성 반응시 생성되는 물질인 메탄올을 고순 도로 정제하여 사용할 수 있도록 설계하였다. 그리고 에 너지 소모량을 최소화하기 위해 용매의 최적 순환유량과 운전압력 그리고 원료 주입단 등을 결정하여 공정 최적 화를 수행하였고 공정의 유틸리티 소모량과 장치사이징 결과를 도출하였다. 이러한 결과는 Table 8에 나타내었 다. Table 8 을 보면 본 공정에서 소요되는 총 냉각수 유량
은 $24,777 \mathrm{~kg} / \mathrm{hr}$ 이고 재비기의 heat duty는 $0.4125 \times 10^{6}$ $\mathrm{kcal} / \mathrm{hr}$ 로 사용되는 총 스팀 유량은 $891.08 \mathrm{~kg} / \mathrm{hr}$ 이다. 그 리고 흡수탑, 이산화탄소 탈거탑, 메탄올 용매 재생탑의 사이징의 경우 최대 직경이 각각 $410.00,490.00,4230.00$ $\mathrm{mm}$ 이었다.

\section{References}

[1] T. A. Semelsberger, R. L. Borup, and H. L. Greene, "Dimethyl Ether (DME) as an Alternative Fuel", Journal of Power Sources, 156, 497 (2006).

DOI: http://dx.doi.org/10.1016/j.jpowsour.2005.05.082

[2] C. Arcoumanis, C. Bae, R. Crookes, and E. Kinoshita, "The potential of dimethylether (DME) as an alternative fuel for compression-ignition engines: A review", Fuel, 87, 1014 (2008).

DOI: http://dx.doi.org/10.1016/j.fuel.2007.06.007

[3] C. W. Choi, W. Cho, Y. S. Baek, and K. H. Row, "Experimental Study on the Synthesis of Dimethyl Ether" J. Korean Ind. Eng. Chem. 17, 125, (2006).

[4] Y. G. Mo, W. Cho, and Y. S. Baek, "Development of Direct DME Synthesis Process" J. Korean Institute of Gas 14, 41, (2010).

[5] J. Gross and G. Sadowiski, "Perturbed-Chain SAFT: An Equation of State Based on a Perturbation Theory for Chain Molecules", Ind. Eng. Chem. Res., 40, 1244, (2001).

DOI: http://dx.doi.org/10.1021/ie0003887

[6] I. Senol., "Perturbed-Chain Statistical Association Fluid

[Table 8] simulation results summary

\begin{tabular}{|c|c|c|c|c|}
\hline \multicolumn{2}{|c|}{ Column } & $\mathrm{CO}_{2}$ absorber & $\mathrm{CO}_{2}$ stripper & $\begin{array}{c}\mathrm{MeOH} \text { solvent } \\
\text { recovery col. }\end{array}$ \\
\hline \multicolumn{2}{|c|}{ Solvent feeding rate to absorber (kmol/hr) } & 188.23 & - & - \\
\hline \multicolumn{2}{|l|}{$\mathrm{CO}_{2}$ removal ratio $(\%)$} & $99.00^{\mathrm{a}}$ & $99.99^{\mathrm{b}}$ & - \\
\hline \multicolumn{2}{|l|}{ Reflux ratio } & - & 0.37 & 1.02 \\
\hline \multicolumn{2}{|c|}{ Reflux molar rate $(\mathrm{kmole} / \mathrm{hr})$} & - & 5.52 & 10.98 \\
\hline \multicolumn{2}{|l|}{ Feed stage location } & $1.00,6.00$ & 5.00 & 8.00 \\
\hline \multicolumn{2}{|c|}{ Condenser duty $\left(10^{6} \mathrm{kcal} / \mathrm{hr}\right)$} & - & -0.0528 & -0.1828 \\
\hline \multicolumn{2}{|c|}{ Cooling water consumption $(\mathrm{kg} / \mathrm{hr})$} & - & $5,302.42$ & $19,474.93$ \\
\hline \multicolumn{2}{|c|}{ Reboiler duty $\left(10^{6} \mathrm{kcal} / \mathrm{hr}\right)$} & - & 0.2444 & 0.1681 \\
\hline \multicolumn{2}{|c|}{ Steam consumption $(\mathrm{kg} / \mathrm{hr})$} & - & 527.93 & 363.15 \\
\hline \multirow{2}{*}{ Column diameter $(\mathrm{mm})$} & Top & 410.00 & 240.00 & 430.00 \\
\hline & Bottom & 410.00 & 490.00 & 430.00 \\
\hline \multicolumn{2}{|l|}{ Packing height (mm) } & $\begin{array}{r}1,560+1,820 \\
(2 \text { beds })\end{array}$ & $\begin{array}{r}1,560+3,120 \\
(2 \text { beds })\end{array}$ & $\begin{array}{r}1,560+3,640 \\
(2 \text { beds })\end{array}$ \\
\hline
\end{tabular}

a: [1-(amounts of $\mathrm{CO}_{2}$ in top gas/amounts of $\mathrm{CO}_{2}$ in feed gas at absorber $\left.)\right] \times 100 \%$

b: [1-(amounts of $\mathrm{CO}_{2}$ in top gas/amounts of $\mathrm{CO}_{2}$ in feed gas at stripper )] $\times 100 \%$ 
Theory (PC-SAFT) Parameters for Propane, Ethylene, and Hydrogen under Supercritical Conditions" Chem. Eng. Sci., 59, 1244, (2011).

[7] S. H. Huang and M. Radosz, "Equation of State for Small, Large, Polydisperse and Associating Molecules", Ind. Eng. Chem. Res., 29, 2284, (1990).

DOI: http://dx.doi.org/10.1021/ie00107a014

[8] S. H. Huang and M. Radosz, "Equation of State for Small, Large, Polydisperse and Associating Molecules: Extention to Fluid Mixtures", Ind. Eng. Chem. Res., 30, 1994, (1991).

DOI: http://dx.doi.org/10.1021/ie00056a050

[9] N. F. Carnahan and K. E. Starling, "Equation of State for Nonattracting Rigid Spheres", J. Chem, Phys., 51, 635, (1969).

DOI: http://dx.doi.org/10.1063/1.1672048

[10] M. S. Wertheim, "Fluids with Highly Directional Attractive Forces. I. Statistical Thermodynamics", J. Stat. Phys., 35, 19, (1984).

DOI: http://dx.doi.org/10.1007/BF01017363

[11] M. S. Wertheim, "Fluids with Highly Directional Attractive Forces. II. Thermodynamics Perturbation Theory and Integral Equations", J. Stat. Phys., 35, 35, (1984).

DOI: http://dx.doi.org/10.1007/BF01017363

[12] W. G. Chapman, K. E. Gubbins, G. Jackson and M. Radoz, "New Reference Equation of State for Associating Liquids", Ind. Eng. Chem. Res., 29, 1709, (1990).

DOI: http://dx.doi.org/10.1021/ie00104a021

[13] H.I. Britt and R.H. Luecke, "The estimation of parameters in nonlinear implicit models", Technometrics, 15, 233-247 (1973).

DOI: http://dx.doi.org/10.1080/00401706.1973.10489037

[14] D. C. Montgomery, "Introduction to Linear Regression Analysis", 1, 51, John Wiley \& Sons Inc, San Francisco, (2012).

[15] J. H. Hong, R. Kobayashi, "Vapor-liquid equilibrium studies for carbon dioxide-methanol systems", Fluid Phase Equilibria, 41, 269, (1988).

DOI: http://dx.doi.org/10.1016/0378-3812(88)80011-6

[16] H. Schlichting, "Experimentelle Bestimmung und Korrelierung der Loeslichkeit verschiedener Loesungsmittel in Hochdruckgasen", Ph. D. Thesis, TU Berlin, Berlin, Germany, (1991).

[17] R. S. RAMALHO, F. M. TILLER, W. J. JAMES, D. W. BUNCH, "A Rapid Method for Obtaining Vapor-Liquid Equilibrium Data. Theoretical Aspects and
Simple and Continuous Distillation Methods", IND. ENG. CHEM., 53, 895, (1961).

DOI: http://dx.doi.org/10.1021/ie50623a023

[18] Z. Zong, X. Yang, X. Zheng, "Determination of Phase Equilibria for Systems Containing Methyl tert -Butyl Ether", Ranliao Huaxue Xuebao, 15, 32, (1987).

\section{김 동 선(Dong Sun Kim)}

[정회원]

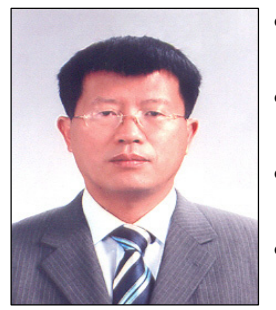

- 1981년 2월 : 한양대학교 공과대 학 화학공학과 (공학학사)

- 1984년 2월 : 한국과학기술원 화 학공학과 (공학석사)

- 1984년 3월 1987년 6월 : 호 남정유 종합기획실 사원

- 1993년 2월 : 미국 Drexel Univ. 화학공학과 (공학박사)

- 1994년 1월 1996년 8월 : 미국 Drexel Univ. 화학공 학과 연구교수

- 1996년 9월 현재 : 공주대학교 화학공학부 교수

<관심분야>

반도체 공정, 열역학, 공정 Simulation

조 정 호(Jungho Cho)

[정회원]

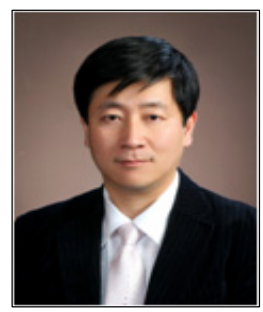

- 1988년 2월 : 한양대학교 공과대 학 화학공학과 (공학사)

- 1991년 8월 : 한국과학기술원 화 학공학과 (공학석사)

- 1998년 2월 : 서울대학교 공과대 학 화학공학과 (공학박사)

- 1991년 1월 1997년 2월 : 대 림산업(주) 공정부 과장

- 1997년 3월 2000년 2월 : 경인여자대학 산업환경공 학부

전임강사

- 2000년 3월 2008년 2월 : 동양대학교 공과대학 생 명화학공학과 조교수

- 2008년 3월 현재 : 공주대학교 화학공학부 부교수

<관심분야>

열역학, 공정 Simulation 


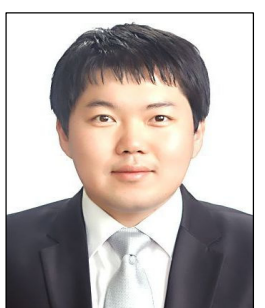

- 2010년 2월 : 호서대학교 공과대학 화학공학과 (공학사)

- 2001년 2월 : 공주대학교 공과대학 화학공학과 (석사)

<관심분야>

열역학, 공정 Simulation

노 재 현(Jaehyun Rho)

[학생회원]

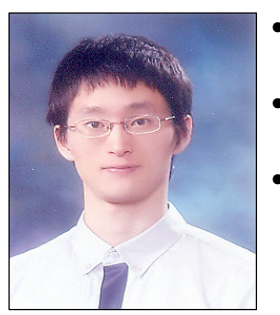

- 2005년 2월 : 호서대학교 공과대학 화학공학과 (공학사)

- 2007년 2월 : 호서대학교 공과대 (공학석사)

- 2007년 3월 : 호서대학교 공 과대(박사과정)

<관심분야>

열역학, 공정 Simulation 